\title{
Mathematical Modeling and Optimization Heat Pipe Systems
}

\author{
Nikita Yu. Sokolova, \\ Vladimir A. Kulagin*b and Dmitry A. Nesterov ${ }^{c}$ \\ ${ }^{a}$ Information satellite systems them. acad. M. F. Reshetneva \\ Zheleznogorsk, Russian Federation \\ ${ }^{b}$ Siberian Federal University, \\ Krasnoyarsk, Russian Federation \\ 'Institute of Computational Modeling SB RAS \\ Division FRC KSC SB RAS \\ Krasnoyarsk, Russian Federation
}

Received 30.06.2021, received in revised form 10.08.2021, accepted 03.09.2021

\begin{abstract}
The results of optimization of the supporting structure of a block of onboard electronic equipment with a built-in single flat heat pipe in the supporting structure with an integrated heat pipe system are presented, using the example of solving a model problem with a single heat source. The comparison was carried out at an equal temperature, occupied volume and for a certain maximum temperature of electrical radio products. The results of computational modeling are presented, demonstrating a comparison of the characteristics of a single flat heat pipe with a system of sequentially located flat heat pipes. Ultimately, the studies carried out have determined the limiting values of the removed thermal power of a single heat pipe, two-level and three-level heat pipe systems with different heat carriers. The versatility of the mathematical model, supplemented by the optimization method, has been confirmed.
\end{abstract}

Keywords: flat heat pipe, heat pipe system, cooling of radio electronic equipment, high heat power density.

Citation: Sokolov N. Yu., Kulagin V. A., Nesterov D. A. Mathematical modeling and optimization heat pipe systems, J. Sib. Fed. Univ. Eng. \& Technol., 2021, 14(7), 860-879. DOI: 10.17516/1999-494X-0352

(C) Siberian Federal University. All rights reserved

This work is licensed under a Creative Commons Attribution-Non Commercial 4.0 International License (CC BY-NC 4.0).

* Corresponding author E-mail address: VKulagin@sfu-kras.ru 


\title{
Математическое моделирование
}

\section{и оптимизация систем тепловых труб}

\author{
Н. Ю. Соколов ${ }^{\text {a }}$ В. А. Кулагин ${ }^{\sigma}$, Д. А. Нестеров ${ }^{\text {в }}$ \\ ${ }^{a}$ Информационные спутниковые системь \\ им. акад. М. Ф. Решетнёва \\ Российская Федерация, Железногорск \\ ${ }^{\sigma}$ Сибирский федеральный университет \\ Российская Федераџия, Красноярск \\ ${ }^{8}$ Институт вычислительного моделирования СО РАН - \\ обособленное подразделение ФИЦ КНЦ СО РАН \\ Российская Федераџия, Красноярск
}

\begin{abstract}
Аннотация. Изложены результаты оптимизации несущей конструкции блока бортовой радиоэлектронной аппаратуры со встроенной одиночной плоской тепловой трубой в несущую конструкцию со встроенной системой тепловых труб на примере решения модельной задачи с одним источником тепла. Сравнение проведено при равной температуре, занимаемом объеме и для определенной максимальной температуры электрорадиоизделий. Приведены результаты вычислительного моделирования, демонстрирующие сравнение характеристик одиночной плоской тепловой трубы с системой последовательно расположенных плоских тепловых труб. В конечном итоге проведенных исследований были выявлены предельные значения отводимой тепловой мощности одиночной тепловой трубы, двухуровневой и трехуровневой систем тепловых труб с разными теплоносителями. Подтверждена универсальность математической модели, дополненной методом оптимизации.
\end{abstract}

Ключевые слова: плоская тепловая труба, система тепловых труб, охлаждение радиоэлектронной аппаратуры, высокая плотность тепловой мощности.

Цитирование: Соколов, Н. Ю. Математическое моделирование и оптимизация систем тепловых труб / Н. Ю. Соколов, В.А. Кулагин, Д. А. Нестеров // Журн. Сиб. федер. ун-та. Техника и технологии, 2021, 14(7). С. 860-879. DOI: 10.17516/1999494X-0352

\section{Введение}

С каждым годом информационный поток становится все больше, поэтому именно спутниковые системы связи представляют собой одну из наиболее динамично развивающихся разновидностей космических информационных систем. Одним из непременных условий надежного функционирования космического аппарата (КА) и его служебных систем, а также оборудования полезной нагрузки является обеспечение необходимого теплового режима всех его компонентов.

Перспективы развития информационных спутниковых систем в России связаны с созданием негерметичных КА. Такие аппараты уже вошли в состав глобальной навигационной системы ГЛОНАСС и в недалеком будущем станут ее основой $[1,2]$. Одновременно идет разработка новых моделей КА с увеличенной мощностью более пяти кВт, сроком активного существования более 12 лет и с повышенными точностными навигационно-временными характеристиками. Одной из главных проблем является обеспечение оптимального теплового режима радиоэлектронной аппаратуры (РЭА) на борту КА. В условиях постоянно возрастающей мощности бортовой аппаратуры и необходимости уменьшения ее объема и массы обеспечение ра-

$$
-861-
$$


боты КА возможно только за счет увеличения эффективности работы систем отвода тепла. Основной принцип функционирования системы обеспечения теплового режима заключается в поддержании требуемого диапазона температур на посадочных местах тепловыделяющего оборудования космического аппарата КА при заданных энергопотреблениях. От этого зависит долговечность и надежность функционирования спутника в целом.

Обеспечение теплового режима современных КА негерметичного исполнения, например спутников связи с увеличенным сроком активного существования, достигается с помощью тепловых труб (ТT). Для минимизации массоэнергетических параметров системы целесообразно использовать принцип естественной, нерегулируемой передачи тепловой мощности с более высокого температурного уровня на низкий. Это обеспечивается отбором тепловой мощности, выделяемой аппаратурой, от ее посадочных мест на термоплатах (панелях), передачей этой мощности на радиационный теплообменник (РТО) и отводом ее с РТО в окружающее пространство. Эффективным средством реализации этого принципа являются тепловые трубы, работающие на основе замкнутого испарительно-конденсационного цикла. ТТ отличаются высокой эффективной теплопроводностью, в десятки раз превышающей теплопроводность металлов [3, 4]. Они обеспечивают эффективный отвод тепла от теплонагруженных электрорадиоизделий (ЭРИ), позволяют трансформировать плотность тепловых потоков, разнести в пространстве источник и приемник теплоты, стабилизировать температуру и уменьшить неравномерность температурного поля по конструкции радиоэлектронной аппаратуры (РЭА). В отличие от систем, имеющих жидкостный контур охлаждения с принудительной циркуляцией теплоносителя, системы из тепловых труб не потребляют электроэнергии, значительно выигрывают в массе и надежности. Поэтому одним из перспективных научно-технических направлений в развитии конструкции современной РЭА КА является внедрение тепловых труб. В настоящее время разработаны и используются плоские тепловые трубы с оригинальной конструкцией корпуса - гипертеплопроводящие секции (ГТПС), которые встраиваются в несущую конструкцию блока РЭА [2, 5]. Тепловые трубы позволяют оптимально решать многие инженерные задачи, связанные с передачей тепла с минимальными потерями, охлаждением и термостатированием или термостабилизацией различных объектов, использующихся как на Земле, так и в космическом пространстве. Важно также развитие методов экспериментального исследования гидродинамики двухфазного газожидкостного течения в микроканале, получение закономерностей режимов течения и определение границ режимов течения, определение потерь на трение для каналов с различной ориентацией относительно вектора силы тяжести [6]. Современные искусственные спутники Земли для связи и телерадиовещания представляют собой КА, оснащенные крупногабаритным негерметичным приборным отсеком в виде блочно-модульной конструкции на основе плоских прямоугольных сотовых панелей [7], несущих на себе теплонагруженные приборы радиоэлектронной бортовой аппаратуры (БА) [8].

Отсутствие в конструкциях ТТ движущихся механических частей, использование для движения теплоносителя капиллярных сил, высокая плотность передаваемого теплового потока при минимальных перепадах температур (термических сопротивлениях) и автономность работы каждой из них, возможность резервирования, минимальное обслуживание и малый удельный вес, бесшумная работа создают им преимущества и обеспечивают надежность и долговечность перед иными способами термостатирования заданного объекта на борту КА. 
Панели с вмонтированными в них ТТ - надежная защита от ударов микрометеоритов [2]. Изотермализирующая природа тепловых труб уменьшает температуры мощных компонентов тепловыделяющего оборудования, увеличивая таким образом надежность их работы. Выигрыш в массе дает возможность распределения массы КА в пользу систем энергопитания, двигателей и полезной нагрузки $[9,10]$. Существуют различные методы проверки работоспособности тепловых труб - термовакуумные испытания (ТВИ) каждого образца, экспресс-контроль в составе РЭА и т. п. В этой связи важным является совершенствование испытательного оборудования, обеспечивающего высокую точность определения характеристик ТТ, что в итоге обеспечит надежность и долговечность работы КА на орбите [11-13].

Основная идея данной работы заключается в разработке новой методики уменьшения массогабаритных характеристик приборов КА, основанного на применении новой математической модели ТТ для описания термодинамических характеристик систем, состоящих из тепловых труб. Главное отличие новой математической модели от существующих, например изложенной в [14-16], в том, что критерием увеличения ТТ в системе тепловых труб служит уменьшение массы системы тепловых труб при добавлении ТТ и уменьшение температурного запаса ЭРИ. Если конструктив рамки отработан и унифицирован, то большой температурный запас $\left(>5^{\circ} \mathrm{C}\right)$ с учетом срока активного существования (САС КА) для ЭРИ во время наземной экспериментальной отработки БА может означать только одно - избыточную массу рамки. Для обеспечения тепловых режимов ЭРИ в блоках с тепловыделением 16-160 Вт в АО «ИСС» разработан конструктив рамок со встроенными гипертеплопроводящими секциями (ГТПС) [5].

Результаты расчета математической модели подтверждены экспериментально на вновь созданной системе ТТ (состоящей из двух ГТПС). Разработанный в итоге блок прибора КА обладает превосходными массогабаритными характеристиками. Система термостабилизации (СТР) современных КА, выпускаемых АО «ИСС», обеспечивает температуры посадочных мест БА в диапазоне от минус 10 до плюс $40{ }^{\circ} \mathrm{C}$. Максимальная рабочая температура ЭРИ определена техническими условиями (ТУ) ЭРИ производителем, также производителем определена максимальная рабочая температура ЭРИ с учетом срока активного существования САС КА. Конструкция БА должна обеспечивать тепловые режимы всех ЭРИ с учетом САС. Масса тепловых труб увеличивается непропорционально длине ТT, что можно заметить на рис. 1, построенном по математической модели Чи [16, 17].

Теория классических тепловых труб, а также модели для расчета температурных характеристик и ограничений на значения тепловых нагрузок хорошо известны. Детальное изложение и развитие можно найти в работах [1, 18-23]. Ниже кратко изложен принцип работы классической тепловой трубы, приводятся основные формулы для оценки капиллярного ограничения для классической тепловой трубы и показана обратная зависимость этого ограничения от длины тепловой трубы.

\section{1. Зависимость максимальной мощности теплопередачи от длины классической тепловой трубы}

Тепловые трубы представляют собой запаянную с обеих сторон герметичную трубу, чаще всего круглого сечения (рис. 2). На внутренней стенке трубы располагается фитиль, содержащей жидкий теплоноситель. При нагреве одного из концов такой трубы жидкий теплоноситель

$$
-863-
$$




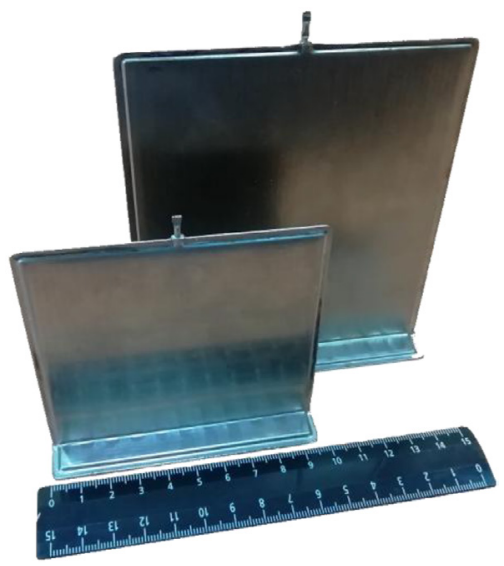

Рис. 1. Внешний вид ГТПС [23]

Fig. 1. External appearance of GTPS [23]

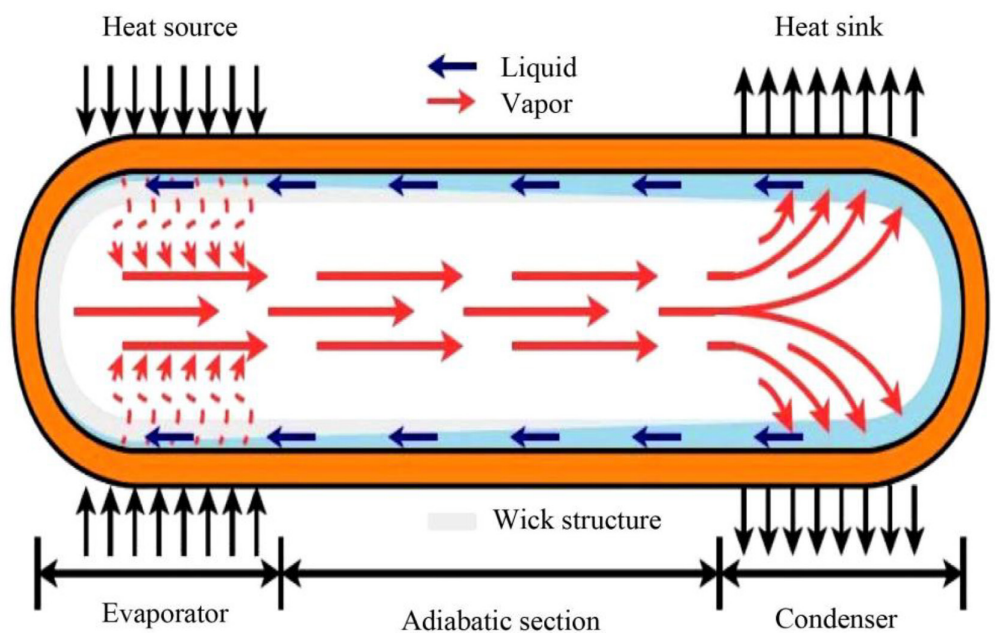

Рис. 2. Схема тепловой трубы [22]

Fig. 2. Scheme of the heat pipe [22]

начинает испаряться из фитиля и в виде пара перемещаться к противоположному концу, где конденсируется и снова впитывается в фитиль. Капиллярные силы фитиля обеспечивают возвращение жидкости к месту подвода тепла. В результате тепловая труба представляет собой пассивный двухфазный тепловой контур, в котором циркуляция теплоносителя осуществляется за счет переносимой тепловой энергии. Для движения теплоносителя не требуется движущихся частей, поэтому работа такого устройства очень надежна. Ключевым преимуществом тепловой трубы является возможность передачи большого количества тепла при очень маленьком перепаде температуры. То есть эффективная теплопроводность устройства может на 1-2 порядка превышать теплопроводность обычных материалов.

Для обеспечения работы тепловой трубы необходимо, чтобы максимальный капиллярный напор фитиля $\Delta \mathrm{P}_{c}$ превышал полное падение давления в трубе: 


$$
\Delta P_{c} \geq \Delta P_{l}+\Delta P_{v}+\Delta P_{g}
$$

где $\Delta \mathrm{P}_{l}$ - перепад давления по жидкости в фитиле; $\Delta \mathrm{P}_{v}$ - перепад давления при движении пара в канале; $\Delta \mathrm{P}_{g}$ - гидростатический перепад давления. С ростом тепловой нагрузки скорость движения жидкости и пара возрастает, следовательно, перепады давлений также увеличиваются. Однако существует максимальное капиллярное давление, которое зависит от свойств фитиля и теплоносителя и может быть определено по уравнению Лапласа-Янга:

$$
\Delta P_{\mathrm{c}}=\frac{2 \sigma \cos \theta}{r_{c}}
$$

где $\sigma$ - коэффициент поверхностного натяжения жидкости; $r_{c}-$ эффективный капиллярный радиус; $\cos \theta$ - предельный краевой угол смачивания. Максимальное значение тепловой нагрузки, при котором выражение (1.1) становится равенством, является капиллярным ограничением. При дальнейшем увеличении тепловой нагрузки фитиль в области подвода тепла начинает осушаться и перепад температуры начинает резко возрастать.

Перепад давления в фитиле тепловой трубы можно оценить на основе закона Дарси для движения жидкости в пористой среде:

$$
\Delta P_{l}=\frac{\mu_{l} L \dot{m}}{\rho_{l} A K}
$$

где $\mu_{l}, \rho_{l}$ - вязкость и плотность жидкости; $A$ - поперечное сечение фитиля; $K$ - проницаемость фитиля; $L$ - расстояние между областью подвода и отвода тепла; $\dot{m}$ - массовый расход жидкости.

Перепад давления в паровом канале можно оценить по формуле движения несжимаемого газа с вязкостью $\mu_{v}$ в цилиндрическом канале с радиусом $r_{v}$ :

$$
\Delta P_{v}=\frac{8 \mu_{v} L \dot{m}}{\pi r_{v}^{4}}
$$

Гидростатический перепад давления равен:

$$
\Delta P_{g}=\rho_{l} g L \sin \varphi,
$$

где $g$ - ускорение свободного падения; $\varphi$ - угол наклона тепловой трубы к горизонту. Учитывая, что массовый расход теплоносителя в тепловой трубе можно выразить через тепловую мощность $Q$ и скрытую теплоту парообразования $H_{e v}$, как

$$
\dot{m}=Q / H_{e v}
$$

можно записать уравнение для предельной тепловой нагрузки $Q_{\max }$ для горизонтального расположения тепловой трубы $(\sin \varphi=0)$ :

$$
Q_{\max }=\frac{C}{L}
$$

где

$$
C=\frac{2 \sigma \cos \theta}{r_{c}}\left(\frac{\mu_{l}}{\rho_{l} A K H_{e v}}+\frac{8 \mu_{v}}{\pi r_{v}^{4} H_{e v}}\right)^{-1} .
$$

Из уравнения (1.7) видно, что максимальная отводимая тепловой трубой тепловая мощность $Q_{\max }$ (капиллярное ограничение) обратно пропорциональна длине, расстоянию между областью подвода и отвода тепла $L$ на тепловой трубе. Таким образом, при замене тепловой

$$
-865-
$$


трубы на две (или более) последовательных тепловых трубы аналогичной длины (суммарно) капиллярное ограничение каждой из них увеличится. Однако при этом общий перепад температуры также возрастет из-за дополнительного теплового сопротивления между тепловыми трубами.

\section{2. Математическая модель теплопередачи в плоских тепловых трубах}

Исследование и сравнение характеристик одиночной плоской тепловой трубы с системой последовательно соединенных плоских тепловых труб проводится с помощью вычислительных экспериментов на примере конструкции гипертеплопроводящих секций. ГТПС представляет собой плоскую тепловую трубу, которая имеет Т-образную форму (рис. 1) и встраивается в алюминиевую рамку блока бортовой РАЭ КА (рис. 3) под платы с радиоэлементами. Она имеет плоскую тонкую герметичную конструкцию, внутри которой находится фитиль из спеченного металлического порошка, заполненный жидким теплоносителем. Фитиль и паровые каналы обеспечивают движение теплоносителя в любом направлении в плоскости тепловой трубы. На поверхности тепловой трубы произвольным образом могут располагаться источники и стоки тепла. В местах подвода тепла жидкость испаряется и движется по паровым каналам к области охлаждения, где пар конденсируется и движется обратно по фитилю. Скрытая теплота парообразования теплоносителя обеспечивает высокую эффективность передачи тепла. Движение рабочего вещества осуществляется за счет капиллярных сил.

Для обеспечения срока активного существования 140000 ч (15 лет) необходимо, чтобы применяемые в аппаратуре ЭРИ функционировали при температуре не более $55{ }^{\circ} \mathrm{C}$ при том, что на установочном месте бортовой РЭА гарантируется температура не более $40{ }^{\circ} \mathrm{C}$. Использование ГТПС в составе блоков бортовой РЭА позволяет значительно снизить перепады температур между источниками тепла и основанием электронного блока.

Вычислительные эксперименты были проведены с использованием программного комплекса для тепловых расчетов бортовой РЭА, содержащей в своем составе блоки со встроен-
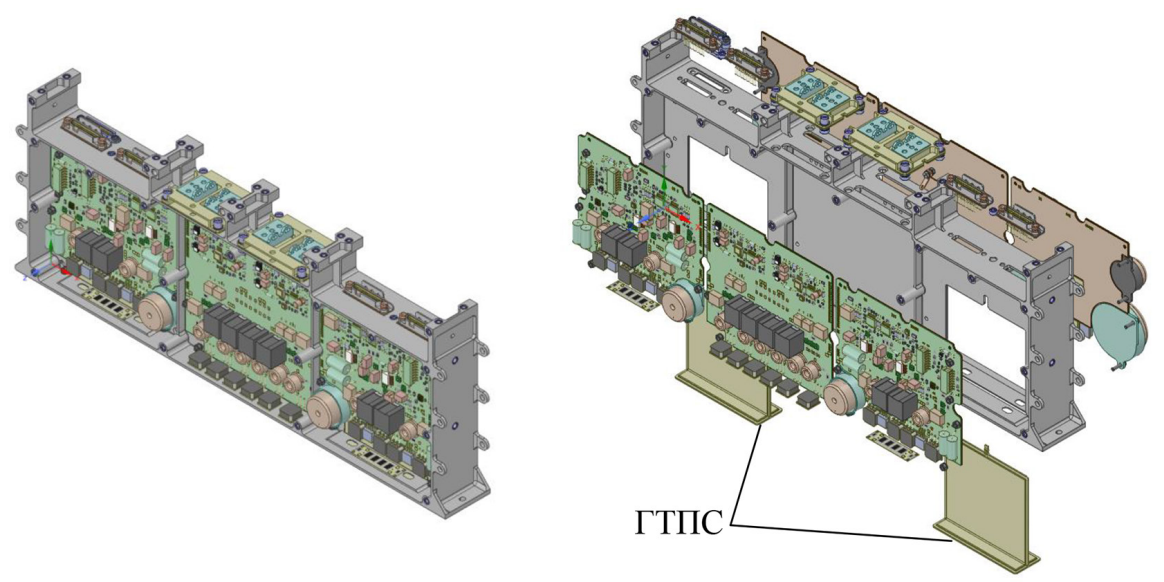

Рис. 3. Модель блока бортовой РЭА с интегрированными ГТПС [23]

Fig. 3. Model of the on-board REA unit with integrated GTPS [23] 
ными ГТПС. Программный комплекс был разработан в ИВМ СО РАН по заказу АО «ИСС» для проектирования бортовой РЭА. Входными данными программного комплекса являются геометрические и теплофизические характеристики узлов прибора, расположение и мощность тепловыделяющих элементов, параметры тепловых контактов, характеристики для учета теплообмена за счет излучения и теплообмена с окружающей средой. При использовании ГТПС учитываются характеристики теплоносителя и материалов фитиля и корпуса тепловой трубы, параметры и геометрия пористой структуры. Предусмотрены различные варианты внешних условий и теплоотвода, соответствующие условиям испытаний РЭА при отработке или функционировании в составе КА на орбите: испытания отдельного блока или прибора в сборе, наличие атмосферы или вакуум, наличие гравитации. В качестве теплоотвода учитываются различные варианты: заданная температура основания, сотовая панель с охлаждающими магистралями, пластина с жидкостными каналами.

Выходными данными программного комплекса являются температуры элементов, тепловые поля конструкций блоков и стенок прибора, распределение температур поверхности теплоотводящего основания, изменение температуры жидкости по длине охлаждающих магистралей. При наличии ГТПС определяются распределения давлений и скоростей паровой и жидкостной фаз теплоносителя, наличие зон осушения или замерзания теплоносителя.

Расчетный модуль программного комплекса использует в работе набор различных математических моделей для решения тепловой задачи. Моделирование теплопередачи в конструкциях блока и прибора без ГТПС сводится к совместному итерационному решению стационарных уравнений теплопроводности и уравнений лучистого теплообмена (при учете излучения). Для плоских тепловых труб были разработаны более сложные модели и алгоритмы, основанные на совместном решении двухмерных уравнений теплопроводности, уравнений сохранения массы жидкости и пара, дополненных уравнениями Дарси. В модели используются усредненные характеристики, которые отражают проницаемость внутренней структуры плоской тепловой трубы для пара и жидкости.

При функционировании ГТПС обычно конвективный механизм переноса тепла является доминирующим. Однако требуется учитывать случаи, когда конвективный перенос тепла становится неэффективным (при температурах теплоносителя, близких к точке замерзания) или при прекращении движения теплоносителя (осушение фитиля, замерзание теплоносителя или блокирование паровых каналов неконденсирующимися газами). В этом случае необходимо учитывать перенос тепла за счет теплопроводности конструкции ГТПС (корпуса и фитиля).

Система уравнений в области ГТПС имеет вид

$$
\begin{aligned}
& \operatorname{div}(-d \cdot \lambda \cdot \nabla T(x, y))+g(x, y) T(x, y)+q_{e v}(x, y)=f(x, y), \\
& \operatorname{div}\left(d_{h p} \frac{\rho_{v}}{\mu_{v}} K_{v} \nabla P_{v}\right)=-\frac{q_{e v}}{H_{e v}}, \\
& \operatorname{div}\left(d_{h p} \frac{\rho_{l}}{\mu_{l}} K_{l} \nabla P_{l}\right)=\frac{q_{e v}}{H_{e v}},
\end{aligned}
$$

где $T(x, y)$ - распределение температуры; $d \cdot \lambda$-произведение толщины и эффективной теплопроводности конструкции тепловой трубы (при отсутствии циркуляции теплоносителя); $g(x, y)$ и $f(x, y)$ - коэффициенты, учитывающие внешние потоки тепла (тепловыделение ЭРИ, сток тепла,

$$
-867-
$$


слагаемые для радиационных потоков тепла и пр.); $q_{e v}(x, y)$ - поглощаемое испаряющимся теплоносителем в тепловой трубе тепло $\left(\mathrm{B} \mathrm{T} / \mathrm{M}^{2}\right) ; P_{l}(x, y)$ и $P_{v}(x, y)$ - давления в жидкостной и паровой фазах теплоносителя; $H_{e v}$ - скрытая теплота парообразования теплоносителя; $\mu$ и $\rho$ - вязкость и плотность фаз теплоносителя; $K_{l}, K_{v}$ - коэффициенты (в общем случае тензоры), определяющие проницаемость капиллярной структуры тепловой трубы для жидкости и пара. Для решения системы (2.1)-(2.3) дополнительно используется соотношение $\nabla P_{v}=\frac{\partial P_{v}}{\partial T_{v}} \nabla T_{v}$, указывающее, что пар внутри тепловой трубы находится на линии насыщения. При этом зависимость производной давления насыщенного пара по температуре может задаваться как отдельная характеристика теплоносителя. Система уравнений (2.1)-(2.3) решается итерационно, при этом на каждой итерации после расчета распределения давлений жидкости и пара проверяется следующее условие:

$$
P_{v}(x, y)-P_{l}(x, y)<P_{c}, \quad P_{c}=\frac{2 \sigma \cos \theta}{r_{c}}
$$

где $r_{c}$ - радиус пор фитиля; $\sigma$ - коэффициент поверхностного натяжения; $\theta$ - предельный угол смачивания материала фитиля теплоносителем. В области, где условие (2.4) не выполняется, фитиль осушается и поглощение тепла при испарении прекращается. Величина $q$ в этой области принимается равной нулю для последующих итераций. Аналогично учитывается условие на замерзание теплоносителя: $T(x, y)>T_{0}$, где $T_{0}$ - температура замерзания.

Разработанный программный комплекс оснащен графическим интерфейсом, обеспечивающим удобную работу с программой, задание входных параметров, получение и анализ результатов расчетов. С целью увеличения точности расчета по результатам экспериментальной проверки ГТПС уточняются значения параметров математической модели (пористость, проницаемость и пр.). На рис. 4 показан пример расчета теплового поля поверхности блока РЭА

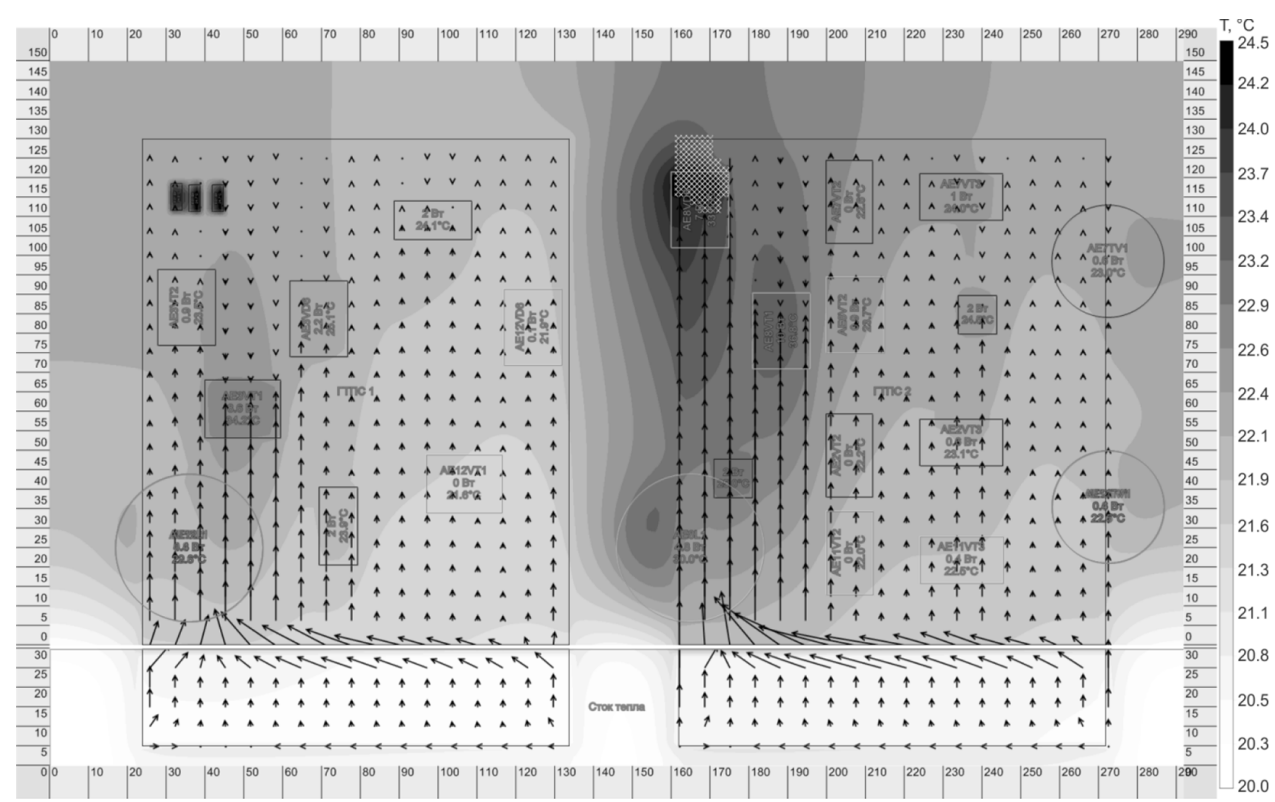

Рис. 4. Температура поверхности блока РЭА и поле скоростей жидкости в фитиле ГТПС [23]

Fig. 4. Surface temperature of the CEA unit and the field of fluid velocities in the GTPS wick [23] 
со встроенными плоскими тепловыми трубами. Дополнительно показано поле скоростей жидкости в капиллярных структурах. На правой тепловой трубе (в левом верхнем углу) выделена область осушения фитиля, которое приводит к локальному увеличению температуры.

\section{3. Сравнительный анализ тепловых характеристик плоской тепловой трубы и системы тепловых труб}

В работе [6] проведен ряд экспериментов по определению максимального значения мощности и плотности мощности, которая может быть отведена с помощью ГТПС, при сконцентрированном подводе тепла, при различном расположении области подвода тепла. В качестве источника тепла использовался транзистор, способный выделять тепловую мощность до 100 Вт и имеющий размер 14 мм $\times 16$ мм (площадь $2,2 \mathrm{~cm}^{2}$ ). Эксперименты проведены для различных вариантов размещения источника тепла на поверхности тепловой трубы. При центральном расположении нагревателя расстояние до холодильника составляло 60 мм, при расположении в углу - 105 мм. Эксперименты проведены для горизонтальной ориентации и при температуре зоны конденсации минус $27^{\circ} \mathrm{C}$.

При расположенном в центре нагревателе осушение фитиля появилось при мощности нагревателя 24 Вт. Температура поверхности тепловой трубы составляла $35^{\circ} \mathrm{C}$. Дальнейшее увеличение мощности нагревателя вызывает линейный рост температуры $1{ }^{\circ} \mathrm{C} / \mathrm{B}$. Для расположенного в углу нагревателя осушение фитиля обнаружено при 13 Вт при температуре поверхности тепловой трубы $35^{\circ} \mathrm{C}$. Дальнейшее увеличение мощности нагревателя вызывает линейный рост температуры $1,2^{\circ} \mathrm{C} / \mathrm{BT}$.

Для вертикально ориентированной ГТПС отводимая от нагревателя мощность до осушения будет значительно меньше, что следует из уравнения (1.1). Также известно, что с уменьшением температуры возрастает динамическая вязкость жидкостей, а для воды в рабочем диапазоне температур РЭА КА существует точка фазового перехода, из чего следует значительное снижение отводимой от нагревателя мощности с уменьшением температуры.

Система последовательно соединенных TT (СТТ) по сумме обеспечиваемых свойств подобна тепловой трубе переменной проводимости, при этом СТТ способна увеличить отводимую мощность по сравнению с одиночной ГТПС. Эффект достигается за счет сокращения длины ТТ в системе и ослабления капиллярного ограничения на предельную мощность для каждой из них. При этом возрастает общий перепад температуры за счет теплового сопротивления на стыках между тепловыми трубами, но уменьшается вязкость на ТТ верхнего уровня. Металлический корпус ТT обеспечивает передачу теплового потока при осушении границы TT. Здесь приведена методика расчета СТТ на примере наихудшего варианта соединения встык - для того, чтобы показать универсальность данного подхода. Принципиально можно выделить три схемы последовательного соединения ТТ (рис. 5).

Тепловое сопротивление соединения ТТ является наиболее важным вопросом при анализе СТT. В работах [14-16] был затронут вопрос соединения ТТ внахлест, однако соединение встык плоских ТТ позволяет без увеличения толщины несущей конструкции блока интегрировать в нее СТТ, аналогично ГТПС. Тепловое сопротивление соединений определено по результатам моделирования в ПО ANSYS. Виды соединений представлены на рис. 6. Модели с достаточной достоверностью описывают вертикально расположенные ТТ в условиях гравитации. В услови-

$$
-869-
$$




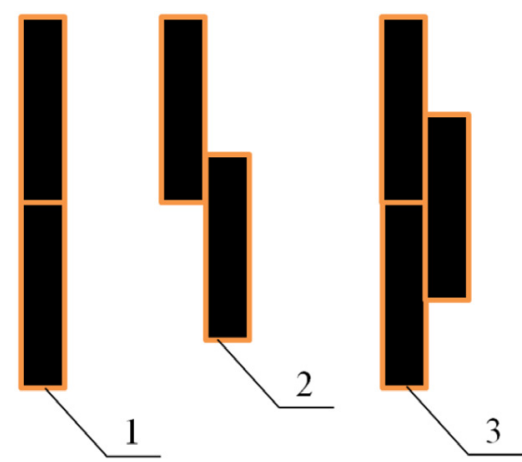

Рис. 5. Возможные схемы соединения ТТ: 1 - встык; 2 - внахлест; 3 - комбинированная

Fig. 5. Possible TT connection schemes: 1 - butt; 2 - overlapping; 3 - combined

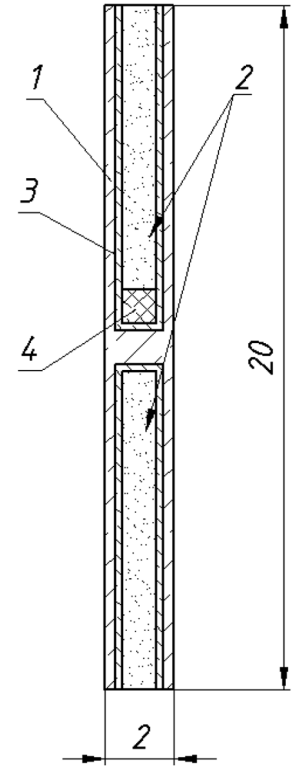

$a$

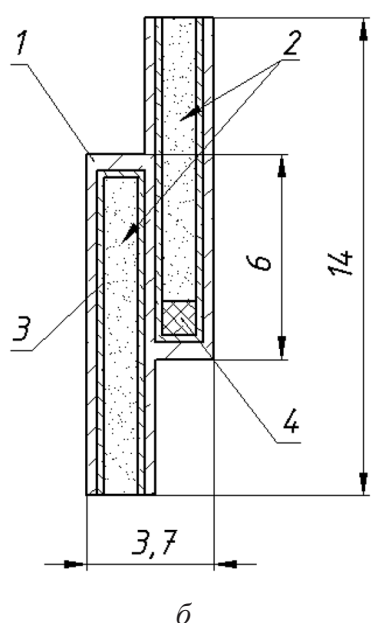

6

Рис. 6. Виды соединений ТТ, где: $a$ - встык; $\sigma$ - внахлест: 1 - стенки несущей конструкции, 2 - газовые каналы, 3 - пористый металл, 4 - слой сконденсированного теплоносителя

Fig. 6. Types of TT connections, where: $a$ - butt; $b$-overlap: 1 - walls of the supporting structure, 2 - gas channels, 3 - porous metal, 4 - layer of condensed coolant

ях невесомости теплоноситель будет ровным слоем расположен по зоне теплообмена. С целью уменьшения негативного влияния слоя жидкости в зоне охлаждения при соединении встык необходимо увеличить толщину стенок ТТ (перераспределить тепловые потоки по металлу). СТТ - это баланс между металлом и ТТ для увеличения надежности, уменьшения массы такой системы охлаждения и создания магистрали (разветвленной сети) тепловых шин.

Минимальная толщина СТТ при соединении встык составляет $2 \cdot 10^{-3} \mathrm{M}$, а при соединении внахлест $-3,7 \cdot 10^{-3}$ м. Толщина стенок несущей конструкции в обоих случаях равняется $3 \cdot 10^{-4} \mathrm{M}$. Теплопроводность несущей конструкции $400 \mathrm{Bт} /(\mathrm{M} \cdot \mathrm{K})$. Толщина пористого металла $2 \cdot 10^{-4}$ м. Теп- 
лопроводность пористого металла $10 \mathrm{BT} /(\mathrm{m} \cdot \mathrm{K})$. В зоне конденсации верхней ТТ будет скапливаться теплоноситель, при этом толщина слоя теплоносителя в худшем случае может составить $1 \cdot 10^{-3}$ м. Эффективная теплопроводность газовых каналов $\approx 10000 \mathrm{BT} /(\mathrm{м} \cdot \mathrm{K})$. Тепловая мощность источника принята равной 100 Вт, длина соединения (ширина ТТ) составляет 0,1 м. По результатам моделирования, тепловое сопротивление соединения ТТ встык равняется 0,015 (K·м)/Вт. Тепловое сопротивление соединения ТТ внахлест составляет 0,006 (К·м)/Вт (рис. 7 и 8).

Вычислительные эксперименты для СТТ (соединение встык) были проведены для одиночной плоской ТТ (медной) и СТТ, состоящей из двух и трех соединенных встык плоских ТТ. Схемы расположения плоских ТТ, зоны отвода тепла и нагрева показаны на рис. 9. Для одиночной плоской ТТ условия моделирования (расположение нагревателя и зоны отвода тепла) полностью совпадают. В области $100 \times 100$ мм на максимальном расстоянии от зоны охлаждения располагается локальный нагреватель, имеющий размер 10 мм $\times 20$ мм (площадь 2 см²). Тепловое сопротивление под нагревателем принято равным $0,28 \mathrm{BT} / \mathrm{K}$, что соответствует толщине клея 0,1 мм с теплопроводностью $1,8 \mathrm{BT} /(\mathrm{м} \cdot \mathrm{K})$. Граница между ТТ имеет толщину металла $2 \cdot 10^{-3}$ м, теплопроводность $120 \mathrm{BT} /(\mathrm{M} \cdot \mathrm{K})$. Дополнительно задано тепловое сопротивление 0,015 (К`м)/Вт между ТТ. Эксперименты проведены для вертикальной ориентации в поле действия гравитационных сил.

Результаты сравнительного анализа характеристик ТТ и СТТ (2 ст.) на модельной задаче с одним источником тепла демонстрируют преимущества системы тепловых труб по сравне-

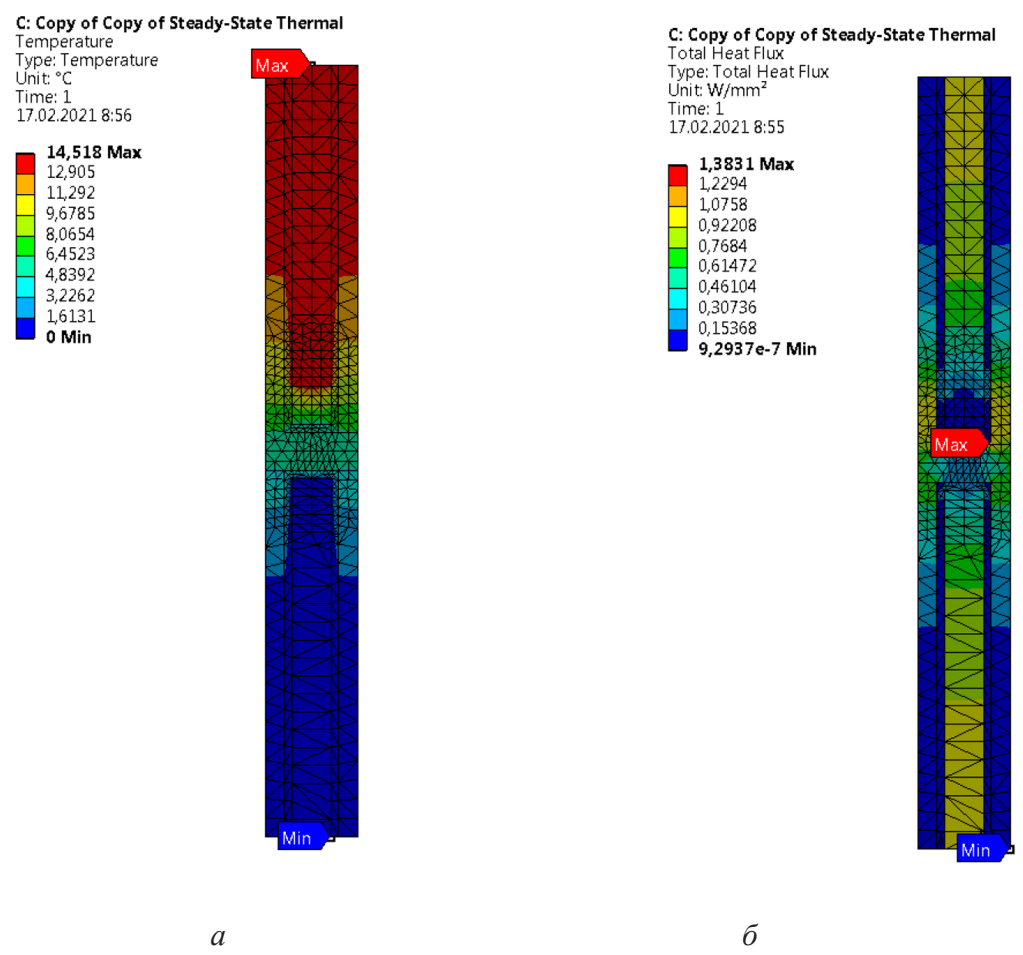

Рис. 7. Результаты моделирования для соединения встык, где: $a$ - распределение температуры; $\sigma$ тепловой поток

Fig. 7. Simulation results for butt joint, where: $a$-temperature distribution, $b$ - heat flux 


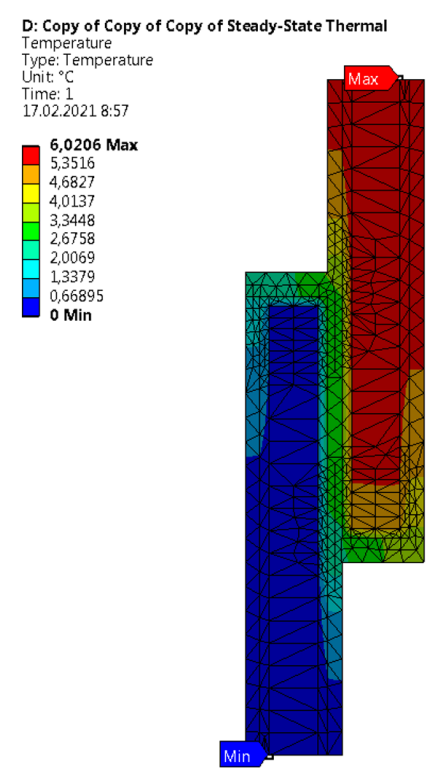

a

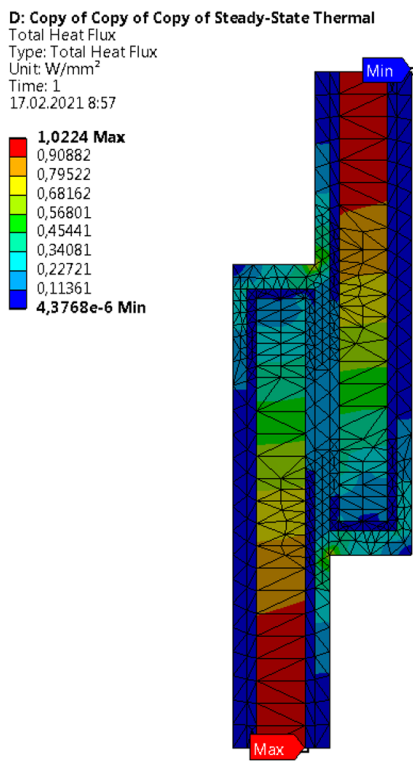

$\sigma$

Рис. 8. Результаты моделирования для соединения внахлест, где: $a$ - распределение температуры; $\sigma$ тепловой поток

Fig. 8. Simulation results for overlapping joints, where: $a$-temperature distribution; $b$ - heat flow

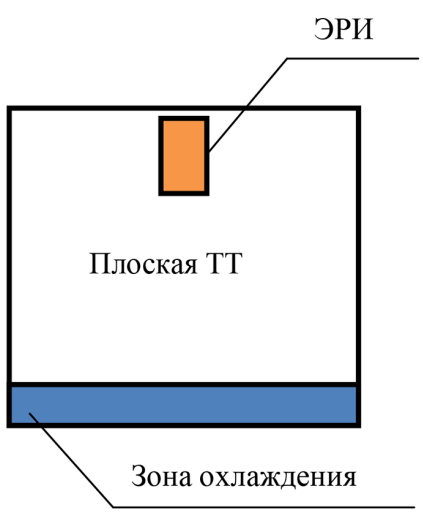

$a$

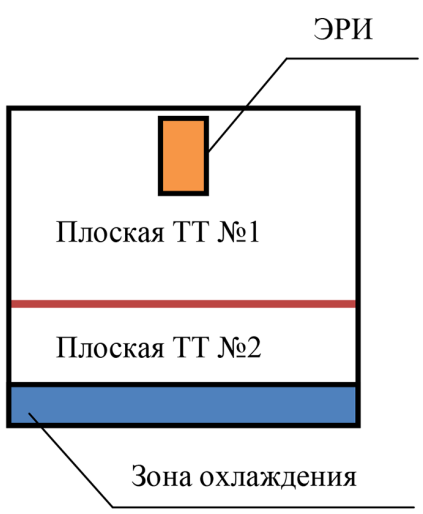

б

Рис. 9. Схема эксперимента: $a$ - плоская ТТ; $\sigma$ - СТТ (2 ст.)

Fig. 9. Scheme of the experiment: $a$ - flat TT; $b$ - CTT (2 tbsp.)

нию с одиночной плоской тепловой трубой с водой в качестве теплоносителя. На рис. 10 и 11 показаны зависимости температуры ЭРИ от их тепловыделения $T(Q)$ для одиночной ТТ и двух последовательно соединенных тепловых труб для разных температур зоны охлаждения. Для одиночной плоской тепловой трубы в диапазоне температур холодильника от минус 20 до $0{ }^{\circ} \mathrm{C}$ наблюдается линейный рост температуры с увеличением мощности, что связано с замерзани- 
ем теплоносителя. Перенос тепла обеспечивается за счет теплопроводности корпуса тепловой трубы. При температуре холодильника $10{ }^{\circ} \mathrm{C}$ вода находится в жидком состоянии, и тепловая труба начинает эффективно передавать тепло, однако при мощности около 5 Вт температура источника тепла начинает резко возрастать, что соответствует достижению капиллярного ограничения и осушению фитиля под источником тепла (рост зеленого графика на рис. 10). При температуре холодильника $20{ }^{\circ} \mathrm{C}$ капиллярное ограничение возникает при $20-25$ Вт. При температуре холодильника $40{ }^{\circ} \mathrm{C}$ резкий рост температуры ЭРИ наблюдается в диапазоне мощности 70-80 Вт. Значение мощности начала осушения фитиля очень зависит от температуры холодильника. Это объясняется зависимостью характеристик воды (в основном водяного пара) от температуры. Плотность пара резко возрастает с ростом температуры. Отсюда возникает техническая проблема - если температура холодильника опускается ниже $10{ }^{\circ} \mathrm{C}$, это очень ограничивает разрешенную мощность источника. Хотя при высокой температуре холодильника мощность могла бы быть значительно выше.

Для СТТ в диапазоне температур холодильника от минус 20 до $0{ }^{\circ} \mathrm{C}$ наблюдается более сложная зависимость температуры от мощности, что объясняется благоприятными условиями на верхней ТТ. Нижняя ТТ замерзшая, но тепловой поток передается по металлическому корпусу. При больших температурах графики $T(Q)$ становятся линейными, что объясняется отсутствием осушения фитиля при рассматриваемых мощностях. Больший наклон графика по сравнению с одиночной тепловой трубой (рис. 10) объясняется дополнительным перепадом температуры на стыке тепловых труб в СТТ.

Для более ясной демонстрации эффекта представлены графики $T(x)$ для одиночной ГТП и СТТ (2 ст.) при разных мощностях источника тепла и разных температурах холодильника (рис. 12-14), где $T$ - температура тепловой трубы, $x$ - расстояние от холодильника. Для одиночной ГТП на графиках видна область перегрева, в которой фитиль не смачивается из-за капиллярного ограничения. На графике для СТТ видно, что осушение не возникает и, несмотря на то, что есть скачок температуры на стыке тепловых труб, итоговая температура источника тепла ниже.

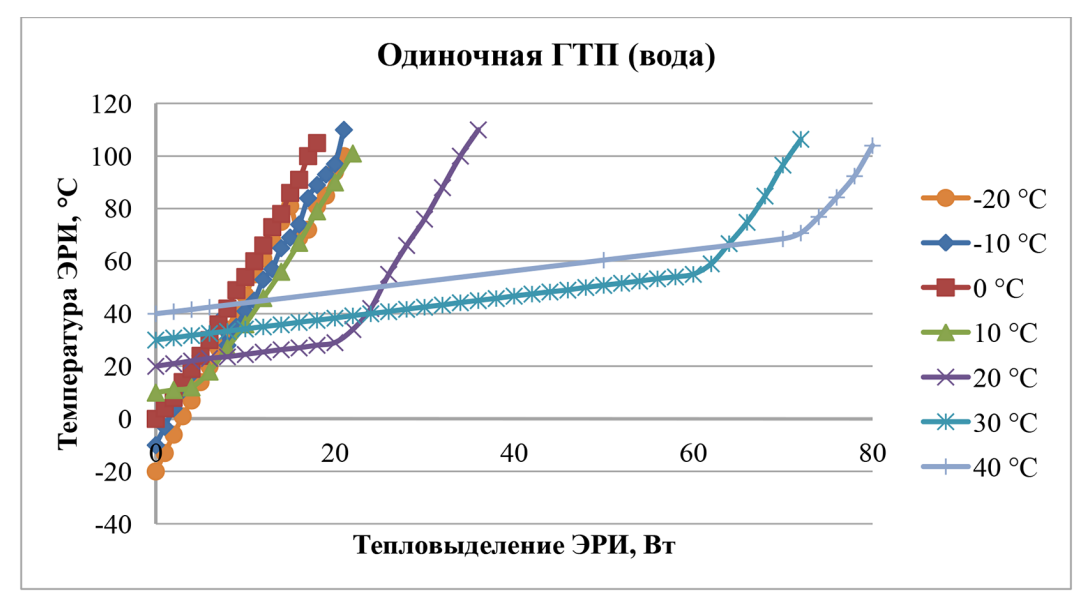

Рис. 10. Зависимость $T(Q)$ от температуры зоны охлаждения

Fig. 10. Dependence of $T(Q)$ on the temperature of the cooling zone

$$
-873-
$$




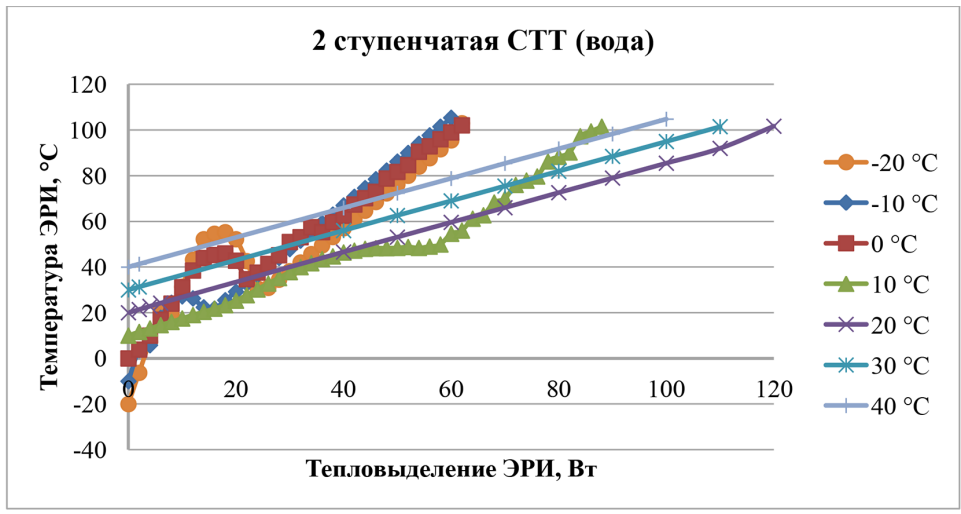

Рис. 11. Зависимость $T(Q)$ от температуры зоны охлаждения

Fig. 11. Dependence of $T(Q)$ on the temperature of the cooling zone

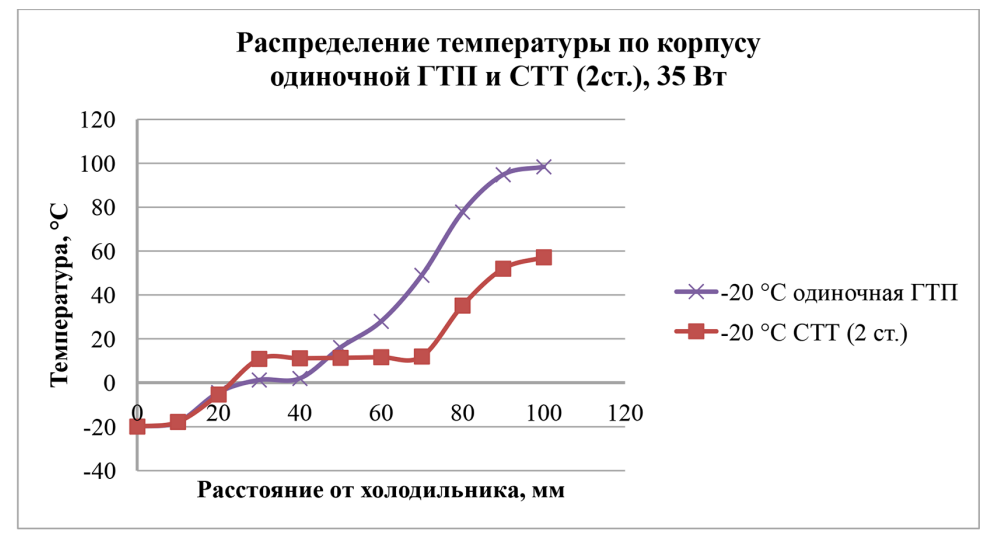

Рис. 12. Зависимость $T(x)$ при температуре холодильника минус $20{ }^{\circ} \mathrm{C}$

Fig. 12. Dependence $T(x)$ at a refrigerator temperature of $-20^{\circ} \mathrm{C}$

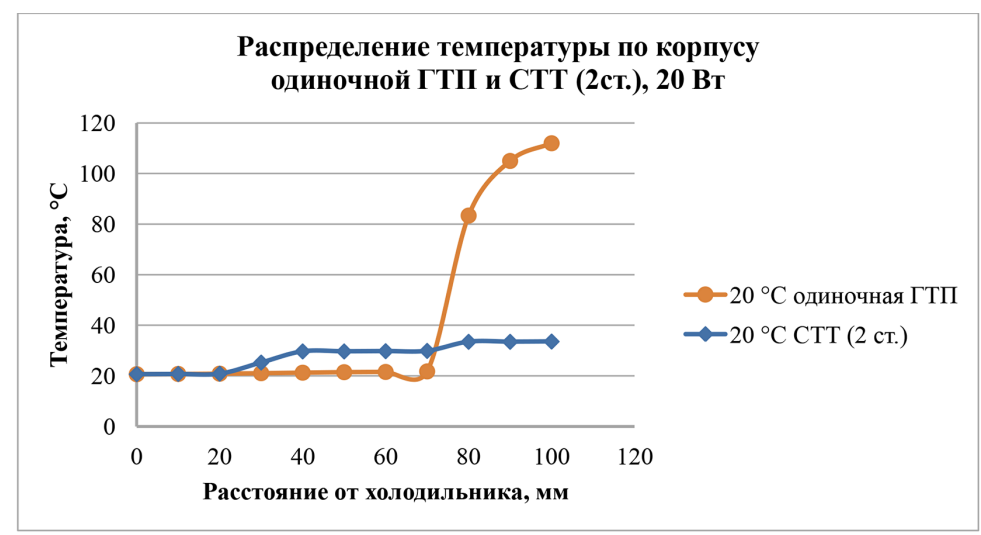

Рис. 13. Зависимость $T(x)$ при температуре холодильника минус $20{ }^{\circ} \mathrm{C}$

Fig. 13. Dependence $T(x)$ at a refrigerator temperature of $-20^{\circ} \mathrm{C}$ 


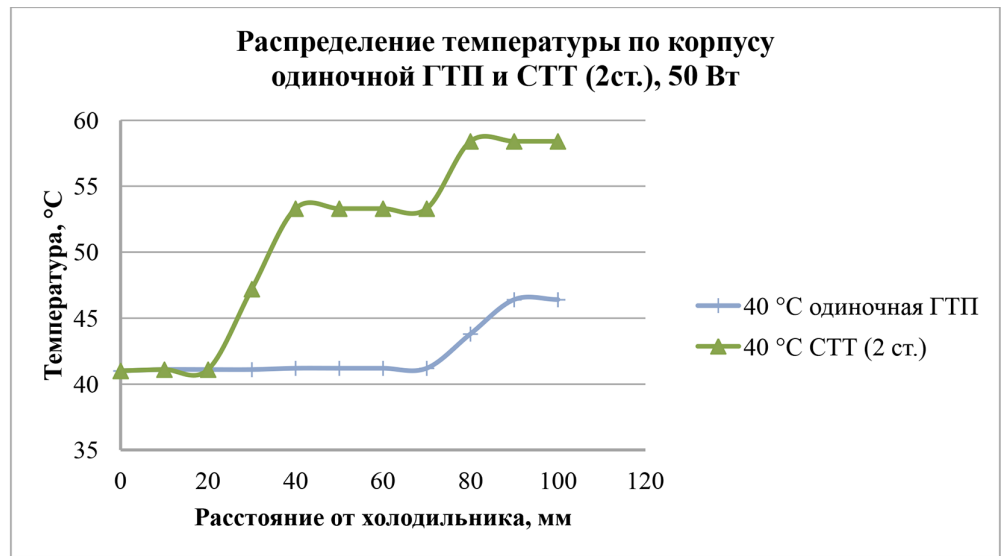

Рис. 14. Зависимость $T(x)$ при температуре холодильника минус $20{ }^{\circ} \mathrm{C}$

Fig. 14. Dependence $T(x)$ at a refrigerator temperature of $-20^{\circ} \mathrm{C}$

\section{4. Определение оптимальных соотношений длин последовательных тепловых труб}

В данном случае эффект зависит от соотношения длин ТТ. Необходимо оптимизировать соотношение длин в системе тепловых труб, чтобы получить максимальную пользу. Для удобства необходимо ввести величину $\gamma=L_{1} /\left(L_{1}+L_{2}\right)$, где $L_{1}-$ длина первой трубы, $L_{2}-$ длина второй трубы (если $\gamma=0,5$, то длины одинаковые). Тепловыделяющие ЭРИ имеют максимальную рабочую температуру порядка $80{ }^{\circ} \mathrm{C}$ для САС 140000 ч, а пассивные ЭРИ имеют рабочую температуру порядка $55^{\circ} \mathrm{C}$ для САС 140000 ч. Поэтому сравнивать необходимо при одновременном выполнении двух условий, тепловыделяющие ЭРИ и пассивные ЭРИ должны находиться в рабочем диапазоне температур. Первое условие: температура ЭРИ должна быть меньше $80^{\circ} \mathrm{C}$. Второе условие: температура всех ЭРИ вблизи (на расстоянии 10 мм) источника тепловыделения не должна превышать $55^{\circ} \mathrm{C}$. Взято несколько соотношений L1/L2, $\gamma=0.1,0.2 \ldots 0.6$ с целью определения оптимального для двух теплоносителей: вода, ацетон. На графиках рис. 15 и 16 показан максимально отводимый тепловой поток при выполнении этих условий. На графиках рис. 15 видно, что для воды существует оптимальное значение $\gamma_{\text {opt }}$ $=0.2$. При таком соотношении допустимые мощности источника тепла максимальны и составляют не менее 60 Вт. Для ацетона оптимальное значение $\gamma_{\text {opt }}=0,5$ (рис. 16). При таком соотношении допустимые мощности источника тепла максимальны и составляют не менее 22 Вт. На графике для одиночной плоской ТТ с водой в качестве теплоносителя видно, что в интервале температур от минус $10{ }^{\circ} \mathrm{C}$ до $40{ }^{\circ} \mathrm{C}$ она обеспечивает тепловой режим ЭРИ с тепловыделением не более 12 Вт, поскольку при низкой температуре теплоноситель замерзает. Плоская ТТ с ацетоном в качестве теплоносителя обеспечивает тепловой режим ЭРИ с тепловыделением не более 10 Вт во всем диапазоне температур. Двухуровневая и трехуровневая СТТ с водой в качестве теплоносителя обеспечивает тепловой режим ЭРИ с тепловыделением не менее 40 Вт, что в 4 раза превышает характеристики одиночной ТТ. Трехуровневая СТТ с ацетоном в качестве теплоносителя обеспечивает тепловой режим ЭРИ с тепловыделением не более 28 Вт. 


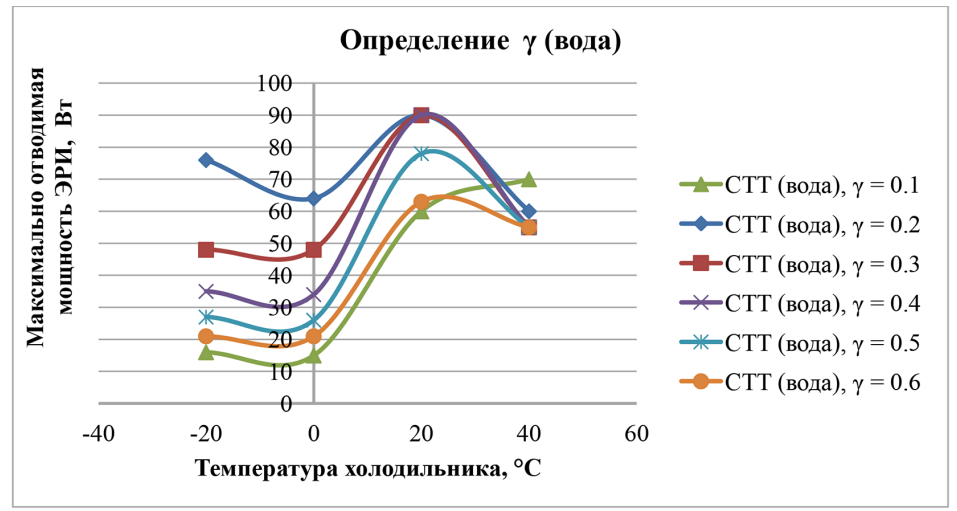

Рис. 15. Оптимизация соотношения $\gamma$ СТТ (вода)

Fig. 15. Optimization of the ratio $\gamma$ CTT (water)

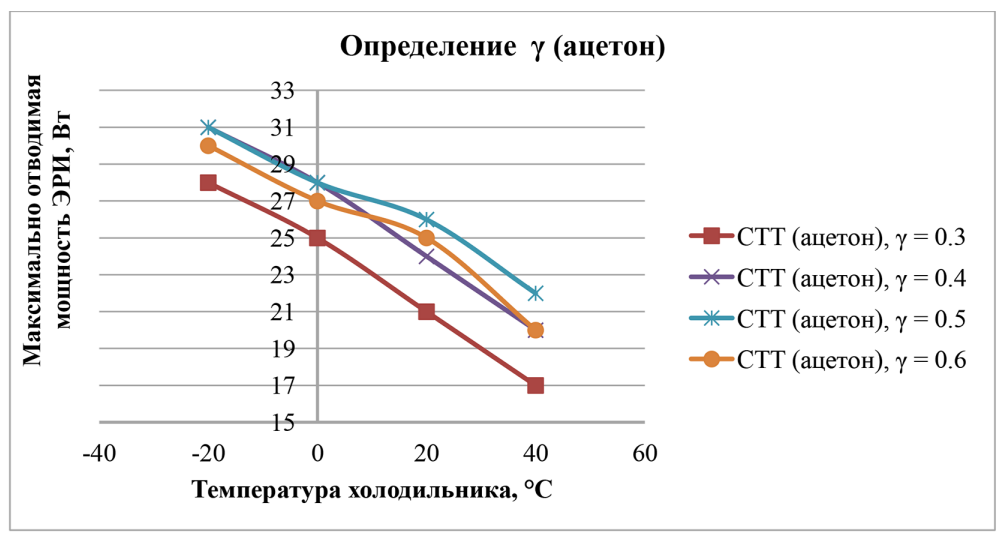

Рис. 16. Оптимизация соотношения $\gamma$ СТТ (ацетон)

Fig. 16. Optimization of the ratio $\gamma$ CTT (acetone)

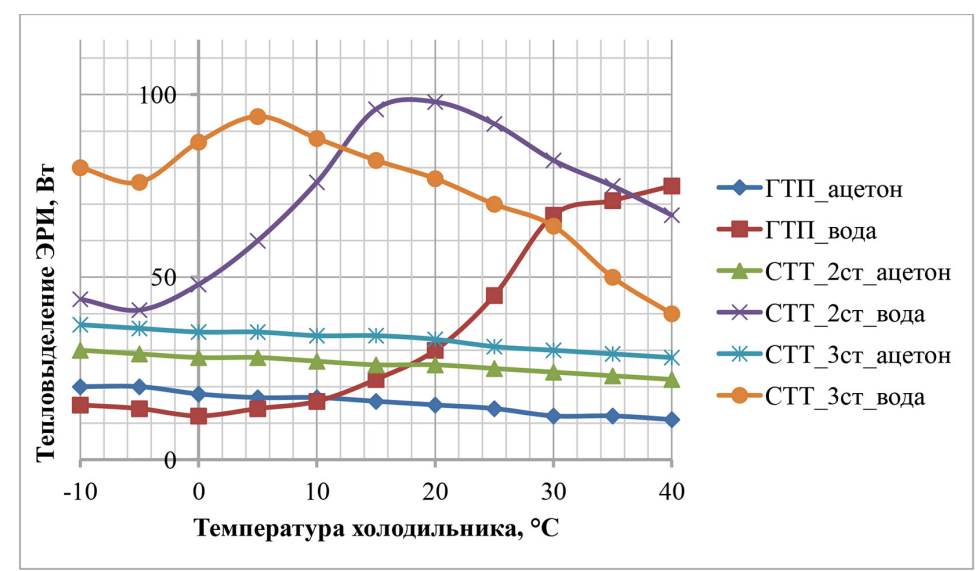

Рис. 17. Зависимость отводимой тепловой мощности нагревателя от температуры зоны охлаждения для разных схем соединения ТТ [23]

Fig. 17. Thermal flux from the heater versus cooling zone temperature for various options of HP connection [23] 
На графиках по определению $\gamma$ (ацетон) видно (рис. 16), что увеличение температуры холодильника отрицательно влияет на максимально отводимую мощность от ЭРИ. Эффект от преобразования в СТТ также наблюдается на теплоносителе ацетон. Также с целью проверки увеличения количества ступеней проведен расчет, результаты которого представлены на рис. 17.

\section{Заключение}

В результате проведенных исследований были установлены предельные значения отводимой тепловой мощности одиночной ТТ, двухуровневой и трехуровневой СТТ с разными теплоносителями. Подтверждена универсальность математической модели, представленной в работе [16], дополненной методом оптимизации. Расчеты проведены на примере модельной задачи с одним источником тепловыделения. Отсюда возникает необходимость распространить результаты исследований для оптимизации блока бортовой РЭА с большим числом источников тепловыделения.

\section{Список литературы / References}

[1] Дан П. Д., Рей Д.А. Тепловые трубы: пер. с англ. М.: Энергия, 1979. 272 с. [Dan P.D., Ray D. A. Heat Pipes. (transl. from English). M., Energiya, 1979. 272 p. (in Russian)]

[2] Деревянко В. А., Нестеров Д. А., Косенко В.Е. и др. Плоские тепловые трубы для отвода тепла от электронной аппаратуры в космических аппаратах. Вестник СибГАУ. 2013. 6(52). 111-116 [Derevyanko V. A., Nesterov D. A., Kosenko V.E., et al. Flat heat pipes for cooling spacecraft electronics, Vestnik SibGAU, 2013, 6(52), 111-116 (in Russian)]

[3] Лукс А.Л., Матвеев А.Г. Анализ основных расчетных и экспериментальных теплофизических характеристик аммиачных тепловых труб повышенной тепловой проводимости из алюминиевых сплавов. Вестник СамГУ. Естественнонаучная серия, 2008, 3(62), 331-357. [Luks A.L., Matveev A.G. Analysis of the main calculated and experimental thermophysical characteristics of ammonia heat pipes of increased thermal conductivity from aluminum alloys. SamSU Bulletin. Natural science series, 2008, 3(62), 331-357 (in Russian)]

[4] Лукс А. Л., Матвеев А.Г., Зеленцов Д.В. Методика расчета тепловых труб, отводящих тепло от тепловыделяющей поверхности. Градостроительство и архитектура, 2018, 8, 1(30), 35-39 [Luks A. L., Matveyev A. G., Zelentsov D. V. Procedure to calculate heat pipes transporting heat from heat dissipating surface, Gradostroitelstvo i arkhitektura, 2018, 8, 1(30), 35-39 (in Russian)]

[5] Пат. 2403692 РФ, МПК Н05К 1/00, Н05К 7/20. Модуль радиоэлектронной аппаратуры с гипертеплопроводящим основанием. Сунцов С.Б., Косенко В.Е., Деревянко В. А.; заявитель и патентообладатель Открытое акционерное общество «Информационные спутниковые системы» имени академика М.Ф. Решетнёва».- № 2009116488/07; заявл. 29.04.2009; опубл. 10.11.2010, Бюл. № 31 [Pat. 2403692 RF, IPC N05K 1/00, N05K 7/20. Radio electronic equipment module with a hyperthermal base. Suntsov S. B., Kosenko V.E., Derevianko V.A.; Applicant and patent holder «Information Satellite Systems» named after academician M. F. Reshetnev» Open Joint Stock Company. - No. 2009116488/07; declared 04/29/2009; publ. 10.11.2010, Bul. No. 31 (in Russian)]

[6] Козулин И. А. Экспериментальное исследование газожидкостного течения в микроканалах с различной ориентаџией. Автореф. дис. ... канд. физ.-мат. наук. Новосибирск, 2013. 23 
c. [Kozulin I. A. Experimental study of gas-liquid flow in microchannels with different orientations. Abstract of thesis. dis. ... Cand. physical-mat. Sciences. Novosibirsk, 2013. 23 p. (in Russian)]

[7] Кузнецов Г.В., Санду С.Ф. Численное моделирование теплофизических процессов в приборных отсеках современных искусственных спутниках Земли. Теплофизика и аэромеханика. 1998. 5(3). 469-477 [Kuznetsov G. V., Sandu S.F. Numerical modeling of thermophysical processes in instrument compartments of modern artificial earth satellites. Thermal physics and aeromechanics. 1998. 5(3). 469-477 (in Russian)]

[8] Kuznetsov G. V., Sandu S. F. Special features of the thermophysical modeling of instrument cubicles of spaceraft. Journal of Engineering Physics and Thermophysics, 2001, 74(6), 1431-1436

[9] Китаев А. И., Лукс А. Л., Порядин А. В. Тепловые трубы повышенной тепловой проводимости как базовые элементы системы терморегулирования в аэрокосмической технике. Becmник СамГУ, 2009, 3-2(19), 98-101 [Kitaev A. I., Lux A. L., Poryadin A. V. Heat pipes with increased thermal conductivity - as basic elements of a thermal control system in aerospace engineering. SamSU Bulletin. 2009. 3-2 (19). 98-101 (in Russian)]

[10] Бирюк В.В., Китаев А.И. Применение тепловых труб для охлаждения РЭА. Becmник СамГУ, 2009, 3-2(19), 342-345 [Biryuk V. V., Kitayev A. I. Heat pipe application in electronics cooling. Vestnik SamGU, 2009, 3-2(19), 342-345 (in Russian)]

[11] Кулагин В.А., Соколов Н.Ю. Разработка оборудования для тестирования тепловых труб. Журнал Сиб. федер. ун-та. Техника и технологии. 2015. 8(6). 774-785. DOI: 10.17516/1999494X-2015-8-6-774-785 [Kulagin V. A., Sokolov N. Yu. Development of equipment to test heat pipes J. Sib. Fed. Univ. Eng. technol. 2015, 8(6), 774-785. DOI: 10.17516/1999-494X-2015-8-6-774-785 (in Russian)]

[12] Кулагин В.А., Соколов Н.Ю. Совершенствование оборудования для проверки Т-образных плоских тепловых труб. Безопасность и живучесть технических систем: Материалы и доклады V Всероссийской конференщии: в 3 m. (Красноярск, 12-16 октября 2015). Красноярск: Сиб. федер. ун-т, 2015. Т. 2. 10-21 [Kulagin V. A., Sokolov N. Yu. Upgrading of testing equipment for T-shaped flat heat pipes. Safety and Survivability of Engineering Systems: Materials and Proceedings of V All-Russian conference: in 3 volumes. (Krasnoyarsk, October 12-16, 2015). Krasnoyarsk: Sib. Fed. Univ. 2015. V. 2. 10-21 (in Russian)]

[13] Kulagin V. A., Sokolov N. Yu. Improving the of thermophysical characteristics of heat pipes. J. Sib. Fed. Univ. Eng. technol., 2017, 10(3), 372-376. DOI: 10.17516/1999-494X-2017-10-3-372-376.

[14] Кулагин В.А., Соколов Н.Ю. Численное исследование характеристик тепловых труб в составе радиоэлектронного оборудования космических аппаратов. Журнал Сиб. федер. унта. Техника и технологии. 2015. 8(6). 769-773. DOI: 10.17516/1999-494X-2015-8-6-769-773 [Kulagin V. A., Sokolov N. Yu. Numerical analysis of characteristics of heat pipes in spacecraft electronics. J. Sib. Fed. Univ. Eng. technol. 2015, 8(6), 769-773. DOI: 10.17516/1999-494X-2015-86-769-773 (in Russian)]

[15] Кулагин В. А., Соколов Н. Ю. Математическое моделирование режимов работы тепловых труб в составе радиоэлектронного оборудования космических аппаратов. Безопасность и живучесть технических систем: Матер. и докл. V Всерос. конф.: в 3 m. (Красноярск, 12 16 октября 2015). Красноярск: Сиб. федер. ун-т, 2015. T. 2. 6-10 [Kulagin V. A., Sokolov N. Yu. Mathematical modeling of operating modes of heat pipes in the composition of radio-electronic 
equipment of spacecraft, Safety and survivability of technical systems: Mater. and reports. V AllRussian Conf:: in 3 vol. (Krasnoyarsk, October 12-16, 2015). Krasnoyarsk: Sib. Feder. un-t, 2015. T. 2. 6-10 (in Russian)]

[16] Кулагин В. А., Соколов Н. Ю. Физико-математическое моделирование предельных характеристик системы тепловых труб в составе радиоэлектронного оборудования космических аппаратов. Безопасность и мониторинг техногенных и природных систем: Матер. и докл. VI Всерос. конф. (Красноярск, 18-21 сент. 2018), Красноярск: СФУ, 2018. 205-210 [Kulagin V. А., Sokolov N. Yu. Physical mathematical modeling of operating limits of a system of heat pipes in spacecraft electronics. Safety and monitoring of technogenic and natural systems: Materials and Proceedings of VI All-Russian Conf. (Krasnoyarsk, Sept.18-21, 2018), Krasnoyarsk: SFU, 2018. 205210 (in Russian)]

[17] Чи С. Тепловые трубы: теория и практика. М.: Машиностроение, 1981. 207 с. [Chi S. Heat pipes: theory and practice. M., Mashinostroyeniye, 1981. 207 p. (in Russian)]

[18] Faghri A. Heat pipe science and technology. UK: Taylor and Frances. 1995. 978 p.

[19] Fahgiri, A. (2014) Heat Pipes, Review, Opportunities and Challenges. Frontiers in Heat Pipes (FHP), 5, 1-48. Doi.org/10.5098/fhp.5.1.

[20] Faghri A. Heat pipe science and technology. Global Digital Press, 2016. 1013 p.

[21] Bahman Zohuri Heat Pipe Design and Technology. Modern Applications for Practical Thermal Management. Springer International Publishing Switzerland, 2016. 513 p. DOI 10.1007/9783-319-29841-2_7.

[22] Shukla, K.N. (2015) Heat Pipe for Aerospace Applications - An Overview. Journal of Electronics. Cooling and Thermal Control, 5, 1-14. http://dx.doi.org/10.4236/jectc.2015.51001.

[23] Соколов Н.Ю., Кулагин В.А., Нестеров Д.А. Система тепловых труб в составе радиоэлектронного оборудования космического аппарата. Журн. Сиб. федер. ун-та. Техника и технологии, 2021, 14(4). 363-377. DOI: 10.17516/1999-494X-0317 [Sokolov N. Yu., Kulagin V. A., Nesterov D. A. Heat pipe system as a component of spacecraft electronics, J. Sib. Fed. Univ. Eng. \& Technol., 2021, 14(4), 363-377. DOI: 10.17516/1999-494X-031 (in Russian)] 